Mal J Nutr 25(2): 309-320, 2019

\title{
Maternal diet and its association with human milk energy and macronutrient composition among exclusively breastfeeding Malaysian Malay mothers
}

\section{Siti Munirah Abdul Basir ${ }^{1}$, Radiah Abdul Ghani ${ }^{2}$, Muhammad Ibrahim ${ }^{1}$, Muhammad Muzaffar Ali Khan Khattak ${ }^{1}$, Muhammad Nor Omar ${ }^{3}$ \& Nor Azwani Mohd Shukri ${ }^{1}$}

${ }^{1}$ Department of Nutrition Sciences, Kulliyyah of Allied Health Sciences, International Islamic University Malaysia (IIUM), Pahang, Malaysia; ${ }^{2}$ Department of Biomedical Sciences, Kulliyyah of Allied Health Sciences, IIUM, Pahang, Malaysia; ${ }^{3}$ Department of Biotechnology, Kulliyyah of Science, IIUM, Pahang, Malaysia

\begin{abstract}
Introduction: This study aimed to determine the relationship of maternal dietary intake with human milk nutritional composition, among Malay mothers during the postpartum period of exclusive breastfeeding. Methods: Human milk samples (20$30 \mathrm{ml})$ were collected from mothers $(n=32)$ at least once monthly for six months postpartum. Macronutrients and fatty acids contents were determined using proximate analysis and gas chromatography methods, respectively. Maternal dietary intakes were recorded using the multiple-pass diet recall method prior to each milk sampling and were analysed using the Nutritionist Pro $^{\mathrm{TM}}$ software. Associations between the milk composition and maternal diet were tested using Spearman correlation. Results: The energy content ranged between 49.6-59.2 $\mathrm{kcal} / 100 \mathrm{ml}$, protein $1.3-1.4 \mathrm{~g} / 100 \mathrm{ml}$, carbohydrate $6.5-9.7 \mathrm{~g} / 100 \mathrm{ml}$ and total fat $6.5-9.7 \mathrm{~g} / 100 \mathrm{ml}$. The polyunsaturated, monounsaturated, and saturated fatty acids concentrations were $10.5-19.1 \%$, 40.6-43.5 \%, and 38.0-49.7 \%, respectively. During confinement (first month postpartum), total energy and total fat content of human milk were the highest whereas total carbohydrate was the lowest, compared to the rest of the exclusive breastfeeding period. In contrast, intakes of total calorie and total fat were the lowest, whereas protein was the highest during this period. However, no associations were detected between human milk nutritional contents and maternal dietary intake. Conclusion: In our study population, the composition of maternal diet and nutritional content of human milk differed between confinement and post-confinement periods. However, the association between maternal diet and human milk composition itself warrants further investigation.
\end{abstract}

Keywords: Breastfeeding, human milk, nutritional composition, maternal diet

\section{INTRODUCTION}

Breastfeeding has been shown to help in promoting survival and optimal development of infants by reducing the incidence of infection, sudden infant death syndrome, obesity, diabetes,

\footnotetext{
*Corresponding author: Dr. Nor Azwani Mohd Shukri Department of Nutrition Sciences, Kulliyyah of Allied Health Sciences, International Islamic University Malaysia, Jalan Sultan Ahmad Shah, 25200 Kuantan, Pahang, Malaysia Tel: (6)09-5715307; Fax: (6)03-5716776; E-mail: norazwani@iium.edu.my doi: https://doi.org/10.31246/mjn-2019-0020
} 
childhood cancer and asthma (Mamun et al., 2015; Horta, Loret De Mola \& Victora, 2015). According to the World Health Organization (WHO), exclusive breastfeeding is defined as the consumption of human milk without supplementation, except for vitamins, minerals, medicines, water and the drops of syrup prescribed by health professionals or clinicians (WHO, 2011). Both the WHO and United Nations Children's Fund (UNICEF) strongly advocate exclusive breastfeeding for the first six months after birth as the optimal way of feeding infants. This is due to the beneficial effects on child health, growth and development as well as its positive implications on maternal wellbeing (WHO, 2009).

Human milk is categorised according to its production stages. Colostrum is a thick yellowish liquid secreted a few days before delivery up to approximately four days postpartum (Ballard \& Morrow, 2013). The milk secreted between the $5^{\text {th }}-14^{\text {th }}$ days postpartum is known as transitional milk whereas mature milk is produced from the $15^{\text {th }}$ day onwards. The content of macronutrients in human milk differs within mothers and across lactation. As human milk changes from colostrum to mature milk, the nutrient composition shifts from low fat and high protein, to a concentration which is high in fat and low in protein (Ballard \& Morrow, 2013).

Milk composition has been reported to be influenced by maternal diets (Maru, Birhanu \& Tessema, 2013). This cross-sectional study investigated the association between cereal- and 'enset'based dietary habits and the level of micronutrients (calcium, magnesium, iron, zinc, and copper) in the human milk samples. It was concluded that human milk calcium and copper content were influenced by dietary intake. Total protein, total fat, saturated fatty acids (SFA), polyunsaturated fatty acids
(PUFA) and monounsaturated fatty acids (MUFA), are among the nutrients in human milk which have been positively associated with maternal dietary intake of these nutrients (Bravi et al., 2016). In this systematic review, it was reported that diet that was high in protein resulted in higher total protein content in the human milk. Higher fat and dairy food intakes were also found to increase the total fat content in the milk. However, these associations were considered weak. As for fatty acids, there were positive correlations of total SFA, MUFA, and PUFA intakes during breastfeeding with their content in human milk.

Maternal dietary intake may be affected by postpartum traditional dietary practices during confinement which are the norm among the Asian communities (Haron \& Hamiz, 2014). Indeed, the majority of Malaysian mothers adhere to certain traditional postpartum regimen and practices which are believed to be helpful in restoring maternal health and well-being after delivery (Fok \& Manager, 2016; Suraya \& Jamaludin, 2014). Commonly, Malaysian women practise confinement for 30-44 days after childbirth, during which time there is an adherence to traditional food taboos is common. It is typical, for example, for some mothers to avoid the intake of some foods such as red meat, seafood, as well as certain fish, fruits and vegetables. These foods are perceived to have properties such as, "cold" (i.e. pumpkin, cucumber and watermelon), "windy" (i.e. cold rice, tapioca, and sweet potato), and "itchy" (i.e. seafood, chicken, and egg) that may hamper health recovery (Nor Azwani et al., 2018). However, these traditional dietary restrictions may affect the quality of maternal diets. A Malaysian study demonstrated that the mean total energy consumed by ethnic Chinese women during confinement is $19 \%$ lower than the Malaysian Recommended 
Nutrients Intake (Poh, Wong \& Karim, 2005). In addition, $>90 \%$ of the mothers surveyed did not meet the nutritional requirements for some micronutrients and minerals such as vitamins $\mathrm{A}$ and $\mathrm{C}$, as well as calcium. There was also a reduced intake of fruits and vegetables which are sources of fibre, vitamins and minerals. This may not only affect the women's health and recovery, but also the production and nutritional quality of human milk.

Studies of the nutritional composition human milk of Malaysian mothers who were on traditional diets and who exclusively breastfed during the postpartum period, are few. This investigation of Malaysian Malay mothers aimed to address this gap in our knowledge.

\section{MATERIALS AND METHODS}

\section{Design}

This was a longitudinal study that assessed the nutritional composition of human milk during six months of exclusive breastfeeding period. It allowed the observation of the nutritional content of human milk at different stages of its production.

\section{Setting}

The study was conducted in the town of Kuantan, which is located on the east coast of Peninsular Malaysia. Data collection and follow-up sessions were carried out from May 2016 to July 2017.

\section{Study population}

The sample size required for this study as calculated using the single mean formula was 152, based on a previous study conducted by Chang et al. (2015). However, the low response rate from eligible study participants rendered random sampling nearly impossible to achieve within the designated study period. A total of 32 Malay mothers were conveniently recruited at several health facilities such as university, government, and private health clinics that were attended by pregnant women for antenatal check-ups in Kuantan area. The women normally lived or worked nearby (within $25 \mathrm{~km}$ radius) and this allowed for the regular data collection and follow up visits, either at the home or workplace of the participants. In addition, online advertisements were sent by email and placed on social media groups in order to increase the participation rate. The inclusion criteria consisted of Malay mothers aged 18-39 years who had delivered singleton infants at full-term ( $\geq 37$ weeks of gestation) and had exclusively breastfed their infants for six months. The exclusion criteria were: diagnosis of pre-existing chronic diseases (such as diabetes mellitus and hypertension) and other complications during pregnancy, tandem nursing, and pre-term delivery. The International Islamic University Malaysia Research Ethics Committee approved the study (IREC 585). Each participant provided a written informed consent before the study commenced.

\section{Data collection}

The sociodemographic information of the participants including age, education level, occupation, number of pregnancies, method of delivery and smoking status was self-reported via face-to-face interview at the time of enrolment. Anthropometry measurements, namely height and weight of the mother, total gestational weight gain and baby birth weight, were also recorded. Maternal weight was measured to the nearest $0.1 \mathrm{~kg}$ using a portable weighing scale (Tanita, Japan), and height to the nearest $0.1 \mathrm{~cm}$ using a portable body meter (SECA, Germany). The total gestational weight gained was then calculated by subtracting the pre-pregnancy weight 
from the current weight measured. The maternal body mass index (BMI) was computed as weight in kilograms divided by height in metres squared. For the infants, the weight was taken by using a portable infant weight scale (Tanita, Japan) and recorded to the nearest 0.1 $\mathrm{kg}$. These measurements were done by a trained research assistant.

Human milk samples were collected on Day 3, 10, 30, 60, 90, 120, 150 and 180, postpartum. Participants were provided with capped tubes to store their human milk in their own refrigerator or freezer until the day of collection. The human milk was expressed either with an electric or manual breast pumps. The participants were asked to empty one breast (at any time of the day) and followed by collection of $20-30 \mathrm{ml}$ of human milk. This was to avoid the collection of only foremilk or hind milk. The frozen or refrigerated human milk was then transferred in a cool bag to the laboratory where it was immediately homogenized and stored at $-40^{\circ} \mathrm{C}$ until analysis.

Maternal dietary intakes were recorded using the technique of multiplepass diet recall for three consecutive days (two weekdays and one weekend day) prior to each milk sampling day and averaged for each time point (Day 3, 10, 30, 60, 90, 120, 150 and 180, postpartum). Participants were asked to recall all foods and beverages they had consumed during the said period. Common household utensils were used to aid the participants in estimating the amount of food they had consumed. For commercial or packed foods, information was obtained from the nutritional information on the package. Any intake of supplements was also recorded and analysed for the maternal dietary intake analysis. These included vitamins and minerals in the form of tablets, capsules, powder, or liquids, which may have contributed to the total calorie and other nutrients intake. The study participants were also asked if they were adhering to traditional confinement dietary practices during the postpartum period.

\section{Data analyses}

Human milk macronutrient analyses

The total protein of human milk was determined by the bicinchoninic acid (BCA) colorimetric assay (Pierce ${ }^{\mathrm{TM}} \mathrm{BCA}$ Protein Assay, Thermo Scientific ${ }^{\mathrm{TM}}$, Illinois, USA), which is considered the most appropriate method for human milk-protein assay (Keller \& Neville, 1986). The total carbohydrate content was determined by using the phenolsulfuric acid method of DuBois et al. (1956). The creamatocrit method was used to determine the concentration of total fats in the human milk (Lucas et al., 1978). This method involves separating the human milk samples into cream and aqueous layers. The total energy value of the human milk samples was computed as the sum of energy contributed by total protein, carbohydrate and fat.

There were two primary steps of fatty acids determination. These were lipid extraction by the Blight and Dyer method (with modifications) and transesterification of lipids. The composition of fatty acids methyl esters was analysed by a gas chromatograph (Agilent 7890A) that was equipped with a flame ionization detector (FID) and Agilent Chromatography Workstation software. The fatty acids methyl ester (FAME) was separated in a capillary column HP-5 $(30 \mathrm{~m} \times 320 \mu \mathrm{m}$ and a film diameter of $0.25 \mu \mathrm{m})$. The carrier gas used was helium which flowed at the rate of $1 \mathrm{ml} / \mathrm{min}$. The injector and detector's temperatures were set at $250^{\circ} \mathrm{C}$ and $270^{\circ} \mathrm{C}$, respectively. The initial oven temperature was from 50$70^{\circ} \mathrm{C}$ at $10^{\circ} \mathrm{C} / \mathrm{min}$ rate, then increased to $170-220^{\circ} \mathrm{C}$ at $2^{\circ} \mathrm{C} / \mathrm{min}$ rate. The final 
temperature of $220^{\circ} \mathrm{C}$ was maintained for 20 minutes. The total run time for the analysis was 57 minutes (Silva et al., 2005). Samples were analysed within 12 hours of transesterification.

\section{Dietary intake}

The average intake of nutrients was calculated using Nutritionist Pro $^{\mathrm{TM}}$ diet analysis software which is based on the Nutrient Composition of Malaysian Foods (Tee et al., 1997) and the United States Department of Agriculture (USDA) Nutrient Database for Standard Reference (USDA Nutrient Data Laboratory, 2006).

\section{Statistical analyses}

The statistical analyses were performed using SPSS Statistics (Version 20). The confidence interval was set at $95 \%$. The normal distribution of data was assessed visually using histogram and Q-Q plots. Descriptive analyses were used to describe the participant characteristics and human milk nutritional composition. The Spearman correlation was used to assess the relationship between the maternal intake and nutrient composition of human milk of each specific time point due to abnormally distributed data. The data were presented as mean \pm standard deviation (SD) or as otherwise stated.

To minimise the effect of measurement errors such as misreporting of energy intake (which could affect the absolute intakes of nutrients), nutrient intakes were statistically adjusted for total energy intake using the residual method. This was done by adding the residue of the difference between the observed nutrient values for each subject and the values predicted by regression equation to the nutrient intake that corresponded with the mean total energy intake of the study population (Willet \& Stampfer, 1986).

\section{RESULTS}

\section{General characteristics}

The demographic data of the study participants are presented in Table 1 . The mean age of the respondents was $31.1 \pm 4.7$ years. About half (53\%) of the study participants were government employees and a majority (88\%) had tertiary education. About $84 \%$ had their infants via normal delivery and $72 \%$ had more than one child. Just over half (53\%) of the mothers had normal BMI with a mean value of $23.5 \mathrm{~kg} / \mathrm{m}^{2}$. In addition, about two thirds of the participants (69\%) had gestational weight gain within the values as recommended by Institute of Medicine (IOM) (2009). The mean birth weight of the infants was $3.1 \pm 0.3$ $\mathrm{kg}$ which was also within the normal weight range. All the study participants $(\mathrm{N}=32)$ reported they had adhered to the traditional confinement dietary practices for the first 40-44 days of postpartum period.

\section{Human milk energy and nutritional composition}

Human milk samples collected in the study were analysed for macronutrients, as summarised in Table 2. The mean energy value of the human milk samples ranged from $49.6 \pm 4.4 \mathrm{kcal} / 100 \mathrm{ml}$ to $59.2 \pm 8.9 \mathrm{kcal} / 100 \mathrm{ml}$ across the study period. It was also shown that the energy content was slightly higher during Day 10 and Day 30. The human milk mean protein composition in this study remained relatively consistent (1.3-1.4 g/100ml) throughout the study period, except for Day 90 where the concentration was slightly higher at 1.6 $\mathrm{g} / 100 \mathrm{ml})$. In addition, the concentration of total fat was found to be higher during Day 10 and Day 30 (7.6 g/100ml and $7.5 \mathrm{~g} / 100 \mathrm{ml}$, respectively) compared to other study periods (3.5-6.4 $\mathrm{g} / 100 \mathrm{ml})$. The mean total carbohydrate concentration was $6.8 \pm 4.1 \mathrm{~g} / 100 \mathrm{ml}$ on 
Table 1. Characteristics of the study participants $(\mathrm{N}=32)$

\begin{tabular}{|c|c|c|c|}
\hline Characteristics & $n(\%)$ & Mean $\pm S D$ & Range \\
\hline Age (years) & & $30.6 \pm 4.4$ & $22-39$ \\
\hline \multicolumn{4}{|l|}{ Employment } \\
\hline Government & $17(53)$ & & \\
\hline Private & $6(19)$ & & \\
\hline Unemployed (housewife) & $6(19)$ & & \\
\hline Studying & $3(9)$ & & \\
\hline \multicolumn{4}{|l|}{ Highest education level } \\
\hline Secondary & $4(12)$ & & \\
\hline Tertiary & $28(88)$ & & \\
\hline \multicolumn{4}{|l|}{ Mode of infant delivery } \\
\hline Normal vaginal delivery & $27(84)$ & & \\
\hline Caesarean section & $5(16)$ & & \\
\hline \multicolumn{4}{|l|}{ Parity } \\
\hline 1 & $9(28)$ & & \\
\hline 2 and more & $23(72)$ & & \\
\hline \multicolumn{4}{|l|}{ Pre-pregnancy BMI (kg/m²) } \\
\hline Underweight & $8(25)$ & $23.5 \pm 4.8$ & $16.4-36.4$ \\
\hline Normal & $17(53)$ & & \\
\hline Overweight/obese & 7 (22) & & \\
\hline \multicolumn{4}{|c|}{ Total gestational weight gain (GWG) $(\mathrm{kg})^{*}$} \\
\hline Less than recommended & $3(9)$ & $11.9 \pm 4.4$ & $5.0-24.0$ \\
\hline Within recommendation & $22(69)$ & & \\
\hline More than recommended & 7 (22) & & \\
\hline Infant's birth weight (kg) & $32(100)$ & $3.1 \pm 0.3$ & $2.6-3.8$ \\
\hline
\end{tabular}

${ }^{*}$ Determined based on IOM Recommended GWG (IOM, 2009)

Day 10 , and $6.5 \pm 3.1 \mathrm{~g} / 100 \mathrm{ml}$ on Day 30. The concentration increased after the first 30 days of breastfeeding period. As for fatty acids, it was found that the mean concentrations of PUFA, MUFA, and SFA varied from $10.5 \%$ to $19.1 \%$, $40.6 \%$ to $43.5 \%$, and $38.0 \%$ to $49.7 \%$ of total fatty acids, respectively.

\section{The association between maternal dietary intake and human milk nutritional composition}

Table 3 demonstrates the total energy and nutrient intakes of the participants in the current study. The total energy intakes during confinement period on Day 10 and Day 30 were found to be the lowest throughout the exclusive breastfeeding period ( $1479 \pm 441 \mathrm{kcal} /$ day and $1532 \pm 418 \mathrm{kcal} /$ day, respectively). In contrast to the human milk nutritional composition, the total fat intakes were lower on Day 10 (33.4 $\pm 16.4 \mathrm{~g} /$ day) and Day 30 (32.7 \pm 15.7 g/day), whereas protein intakes on those days were higher (Day 10: 70.6 $\pm 9.7 \mathrm{~g} /$ day and Day 30: $72.0 \pm 17.5 \mathrm{~g} /$ day), than at other time points of the exclusive breastfeeding period. In addition, fatty acids intake (SFA, MUFA, and PUFA) were also the lowest during the confinement period.

Tables 4 and 5 show the associations between mean total energy and macronutrient composition in the maternal diet and in their human milk at each time point. In the current study, there was no correlation between maternal total calorie intake and the energy value of human milk in any of the time-points. The same could be observed with carbohydrate composition in the diet and in human milk. For 

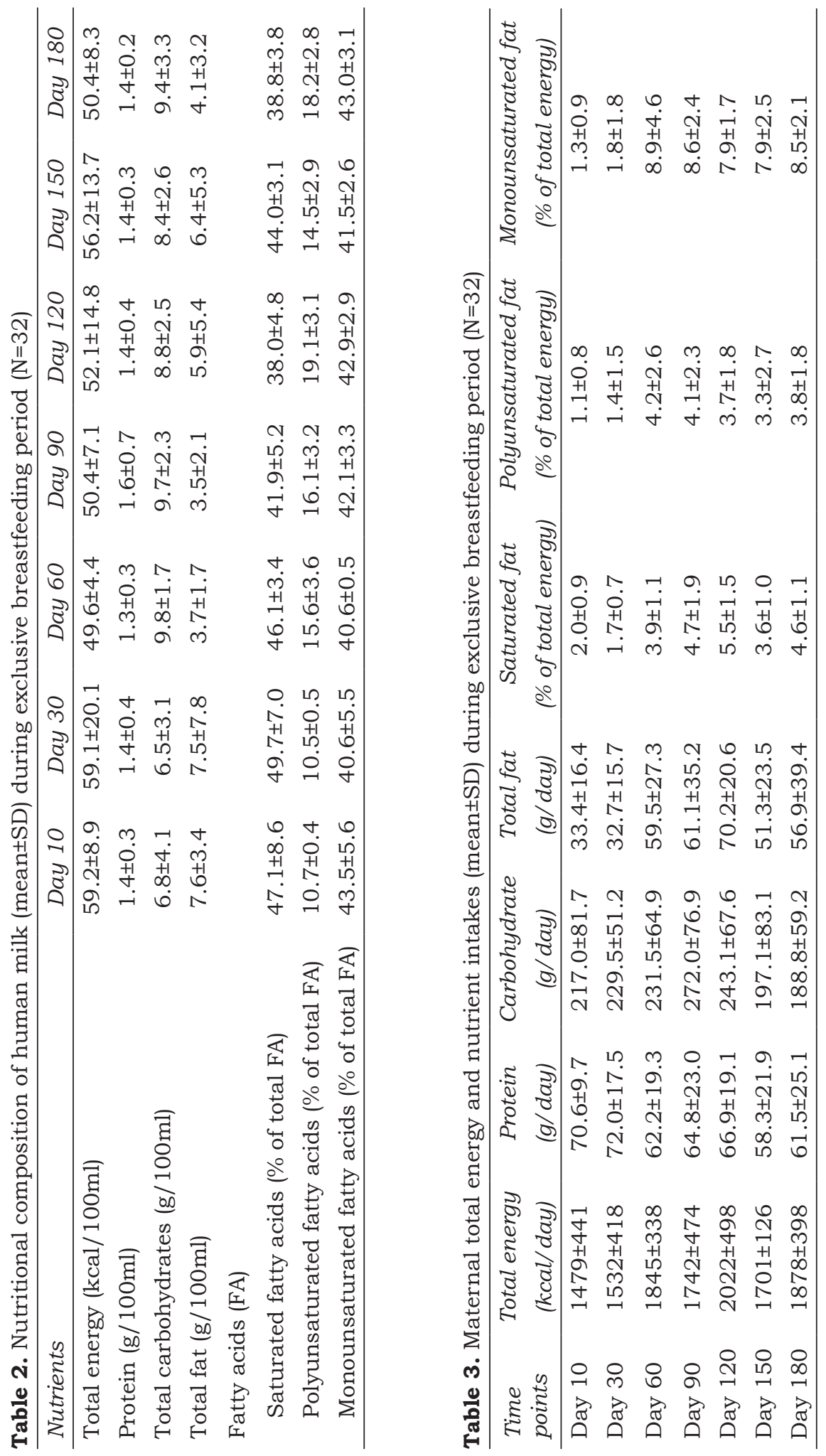
Table 4. Relationship between maternal means of calorie and macronutrients intake and human milk energy and macronutrients composition of each time point $(\mathrm{N}=32)$

\begin{tabular}{|c|c|c|c|c|c|c|c|c|}
\hline \multirow[b]{2}{*}{$\begin{array}{l}\text { Time } \\
\text { points }\end{array}$} & \multicolumn{2}{|c|}{ Energy } & \multicolumn{2}{|c|}{ Protein } & \multicolumn{2}{|c|}{ Carbohydrate } & \multicolumn{2}{|c|}{ Fat } \\
\hline & $r$-coefficient & $p$-value ${ }^{t}$ & $r$-coefficient & $p$-value ${ }^{t}$ & $r$-coefficient & $p$-value ${ }^{t}$ & $r$-coefficient & $p$-value ${ }^{\dagger}$ \\
\hline Day 10 & -0.305 & 0.493 & -0.400 & 0.505 & -0.564 & 0.322 & 0.400 & 0.505 \\
\hline Day 30 & -0.063 & 0.845 & -0.074 & 0.820 & 0.413 & 0.183 & 0.119 & 0.712 \\
\hline Day 60 & -0.217 & 0.498 & -0.075 & 0.791 & -0.049 & 0.880 & -0.393 & 0.206 \\
\hline Day 90 & -0.034 & 0.904 & -0.075 & 0.791 & -0.421 & 0.118 & -0.136 & 0.629 \\
\hline Day 120 & 0.018 & 0.957 & -0.687 & $0.014^{*}$ & -0.119 & 0.713 & 0.536 & 0.072 \\
\hline Day 150 & -0.557 & 0.060 & 0.116 & 0.721 & -0.336 & 0.286 & -0.175 & 0.586 \\
\hline Day 180 & -0.033 & 0.932 & 0.293 & 0.444 & -0.250 & 0.516 & 0.083 & 0.831 \\
\hline
\end{tabular}

${ }^{\dagger}$ Spearman correlation after adjustment of nutrient intakes

${ }^{*} p<0.05$

Table 5. Relationship between maternal fatty acids intake and human milk fatty acids composition of each time point $(\mathrm{N}=32)$

\begin{tabular}{lcccccc}
\hline \multirow{2}{*}{$\begin{array}{l}\text { Time } \\
\text { points }\end{array}$} & \multicolumn{2}{c}{ Saturated fat } & \multicolumn{2}{c}{ Polyunsaturated fat } & \multicolumn{2}{c}{ Monounsaturated fat } \\
\cline { 2 - 6 } & $r$-coefficient & $p$-value & $r$-coefficient & $p$-value & $r$-coefficient & $p$-value \\
\hline Day 10 & -0.050 & 0.391 & -0.200 & 0.747 & -0.205 & 0.741 \\
Day 30 & 0.000 & 1.000 & 0.678 & $0.015^{*}$ & 0.352 & 0.261 \\
Day 60 & -0.049 & 0.880 & 0.172 & 0.594 & -0.194 & 0.546 \\
Day 90 & -0.186 & 0.508 & -0.143 & 0.612 & 0.085 & 0.763 \\
Day 120 & 0.527 & 0.117 & -0.182 & 0.593 & 0.243 & 0.472 \\
Day 150 & 0.336 & 0.312 & 0.082 & 0.811 & 0.102 & 0.766 \\
Day 180 & -0.050 & 0.898 & -0.075 & 0.847 & -0.293 & 0.444 \\
\hline
\end{tabular}

${ }^{\dagger}$ Spearman correlation after adjustment of nutrient intakes ${ }^{*} p<0.05$

the protein, there was a significant negative correlation of maternal protein intake and its concentration in the human milk only at Day $120(r=-0.687$, $p$-value $=0.014)$. In addition, there were no significant correlations between maternal dietary intake of total fat or fatty acids (SFA, PUFA, and MUFA) and their concentrations in human milk samples, except for PUFA at Day $30(r$ $=0.678, p$-value $=0.015$ ) .

\section{DISCUSSION}

The energy and nutrient composition of breastmilk showed some variation throughout the exclusive breastfeeding period. The mean energy content of their milk samples in the current study was $49.6 \pm 4.4$ to $59.2 \pm 8.9 \mathrm{kcal} / 100 \mathrm{ml}$. On the average, the energy content of mature milk (from Day 15 postpartum onwards) was 11.1-16.1 kcal/100ml lower compared to what was found by Jenness (1979) in a Western study (65$70 \mathrm{kcal} / 100 \mathrm{ml})$. Similarly, this value is also $11.1 \mathrm{kcal} / 100 \mathrm{ml}$ lower than the data from a longitudinal study of Egyptian women in which the mean energy concentration of their milk samples from one to four months of 
breastfeeding were 66.0, 65.4, 64.7, and $63.9 \mathrm{kcal} / 100 \mathrm{ml}$ (Soliman, Soliman \& Bakr, 2014). This may be generally due to the different diets among the Western, Middle Eastern, and Asian populations. However, a study of breastfeeding women from four different regions of Shanghai (Qian et al., 2010), found that the mean energy content of their milk samples to be between 57.0 - $63.8 \mathrm{kcal} / 100 \mathrm{ml}$, which was slightly higher than the value found in the current study.

Over the first four to six months, the protein level of human milk was found to be similarly decreasing as lactation progressed in mothers who had delivered their babies prematurely (at $<28$ weeks of gestation) as well as in those who delivered at term (Bauer \& Gerss, 2011). It decreased rapidly during the first month of lactation and continued to decline but much more slowly after that (Lonnerdal, 2003). We found that the protein concentration in our samples were relatively consistent throughout the exclusive breastfeeding period, except for Day 90. Our finding of $1.4 \mathrm{~g} / 100 \mathrm{ml}$ was similar to that of a South Korean study where protein concentration was also $1.4 \mathrm{~g} / 100 \mathrm{ml}$ (Chang et al., 2015) but higher than that of a study in China by Yang et al. (2014) which was $0.9 \mathrm{~g} / 100 \mathrm{ml}$.

The total carbohydrate concentration during the first 30 days was lower whereas the concentrations after 30 days were higher compared to the reference range of $7.2-7.7 \mathrm{~g} / 100 \mathrm{ml}$ (Nommsen et al., 1991). Human milk macronutrient studies specifically on carbohydrates, generally assessed lactose concentration instead of total carbohydrates contents. Lactose concentrations may vary from 6.3-8.1 g/100ml (Yang et al., 2014). This may explain the results found in the present study. However, carbohydrate concentrations in breastfeeding women in Shanghai were between $7.2-8.1 \mathrm{~g} / 100 \mathrm{ml}$
(Qian et al., 2010). The difference in carbohydrates concentration from the present study may be because of the different method of analysis as Qian and colleagues calculated carbohydrates concentrations using a formula (carbohydrate content $=$ Total solids (ash + protein + fat), as opposed to using total carbohydrates proximate analysis.

The fat concentration was also higher than what some others have found (e.g. Nommsen, 1991 reported 2.2-5.0 $\mathrm{g} / 100 \mathrm{ml})$. There was a pattern of reducing of fat concentration in the milk samples as the lactation period progressed. A study by Soliman and colleagues (2014) also found that the fat concentrations reduced as the age of infants increased. On the contrary, a systematic review of 35 breastmilk studies in China revealed that human milk fat concentration was higher in mature milk $(3.4 \pm 1.2 \mathrm{~g} / 100 \mathrm{ml})$ compared to colostrum $(2.4 \pm 1.2$ g/100ml) and transitional milk (3.1 \pm 1.2 g/100ml) (Yang et al., 2018). Human milk fat concentration is the most variable constituent (Picciano, 2001). It may be affected by several factors such as breastmilk volume, parity and maternal diet.

The SFA level in the present study is comparatively lower than that reported in an older study by Kneebone, Kneebone and Gibson (1985) among breastfeeding women in Penang (38.0$49.7 \%$ vs. $52.7 \pm 5.4 \%$ ). In addition, our PUFA levels were much lower (10.5$19.1 \%$ vs. $47.7 \pm 5.4 \%)$ but our MUFA concentrations were slightly higher (40.6-43.5 vs. $36.3 \pm 4.8 \%$ ) compared to the older study. Other studies have reported varied SFA concentrations between 26-51 \% (Kresic et al., 2013). This might have been because of the different diets among these populations. However, this could not be confirmed as none of the authors measured the dietary intakes of their subjects. 
In the present study, maternal energy intake was not associated with the energy value of the human milk. This is in agreement with the findings of a systematic review study which concluded that maternal total calorie intake did not have any influence on the calorie concentration of the human milk (Bravi et al., 2016). The authors, however, found that high fat and low carbohydrate diets resulted in higher caloric content of the milk. Their findings suggest that the energy content of the human milk may not be contributed by the total calorie intake per se, but more by the proportion of maternal carbohydrate and total fat intakes (Bravi et al., 2016). At the fourth month of breastfeeding, protein intake showed a significant negative strong correlation with its concentration in the human milk. Even though the dietary protein intake at that time was lower than the first 30 days of postpartum, the level of protein in the milk remains consistent throughout the breastfeeding period, as discussed earlier. This shows that the protein content of the human milk may not be affected by dietary intake, as was also indicated by other studies (Ogechi \& Irene, 2013; Nommsen et al., 1991). This may be influenced by the different techniques used to analyse the macronutrients content of human milk. In addition, the human milk protein composition may also be influenced by other factors such as the endogenous production by mammary glands as well as maternal body stores (Emmet \& Rogers, 1997).

This is a longitudinal study of the changes of the human milk nutritional composition throughout the period of exclusive breastfeeding. However, this study had only a small number of participants due to response rate from the target population within the stipulated time frame.

\section{CONCLUSION}

Based on the observations of the current study, the energy and nutrient composition of human milk within the study population showed some variation throughout the period of exclusive breastfeeding. Compared to the rest of the exclusive breastfeeding period, total fat content of human milk was the highest whereas total carbohydrate was the lowest during confinement (first month postpartum). The human milk nutritional content in the current study was also found to vary from the findings of other populations. This study has reported the concentrations of the nutritional constituents of human milk during exclusive breastfeeding period among the study population but it did not find any association of these with maternal diet. Future research should be conducted with a larger sample size to substantiate these findings.

\section{Acknowledgments}

The researchers would like to express their gratitude to all the healthcare centres, their staff, and the participants for their cooperation and contribution towards this study. The study was funded by the International Islamic University Malaysia Research Initiative Grant (RIGS) 2015 (Project ID: RIGS15-014-0014).

\section{Authors' contributions}

NAMS, principal investigator, conceptualized and designed the study, prepared the draft of the manuscript and reviewed the manuscript. SMAB, conducted the study, data analysis and interpretation, and assisted in drafting of the manuscript; MI, assisted in conceptualizing and designing the study, provided advice on data analysis and interpretation and reviewed the manuscript; MMAKK, MNO and RAG, provided advice on data analysis and interpretation and reviewed the manuscript.

\section{Conflict of interest}

The authors have declared no conflict of interest. 


\section{References}

Ballard O \& Morrow AL (2013). Human milk composition: nutrients and bioctive factors. Pediatr Clin North Am 60(1): 49-74. doi: 10.1016/j.pcl.2012.10.002.Human.

Bauer J \& Gerss J (2011). Longitudinal analysis of macronutrients and minerals in human milk produced by mothers of preterm infants. Clin Nutr 30(2):215-220.

Bravi F, Wiens F, Decarli A, Dal Pont A, Agostoni C \& Ferraroni M (2016). Impact of maternal nutrition on breast-milk composition: a systematic review. Am J Clin Nutr 104(3):646662. doi: 10.3945/ajcn.115.120881.

Chang N, Jung JA, Kim H, Jo A, Kang S, Lee SW, Yi H, Kim J, Yim JG \& Jung BM (2015). Macronutrient composition of human milk from korean mothers of full term infants born at 37-42 gestational weeks. Nutr Res Pract 9(4):433-438. doi: 10.4162/nrp.2015.9.4.433.

DuBois M, Gilles KA, Hamilton JK, Rebers PA \& Smith F (1956). Calorimetric method for determination of sugars and related substances. Anal Chem 28:350-356.

Emmett PM \& Rogers IS (1997). Properties of human milk and their relationship with maternal nutrition. Early Hum Dev 49: S7-28.

Fok D \& Manager FA (2016). A comparison of practices during the confinement period among Chinese, Malay, and Indian mothers in Singapore. Europe PMC Funders Group 43(3):247-254. doi:10.1111/birt. 12233.A.

Haron H \& Hamiz M (2014). An ontological model for indigenous knowledge of Malay confinement dietary. J. Softw 9(5):1302-1312. doi: 10.4304/ jsw.9.5.1302-1312.

Horta BL, Loret De Mola C \& Victora CG (2015). Long-term consequences of breastfeeding on cholesterol, obesity, systolic blood pressure and type 2 diabetes: A systematic review and metaanalysis. Acta Paediatr, Int J Pediatr 104:3037. http://doi.org/10.1111/apa.13133.

Institute of Medicine (2009). Weight Gain During Pregnancy: Reexamining the Guidelines. Rasmussen KM \& Yaktine AL (eds). The National Academies Press, United States of America.

Jenness R (1979). The composition of human milk. Semin Perinatol 3(3):225-239.

Keller RP \& Neville MC (1986). Determination of total protein in human milk: comparison of methods. Clin Chem 32(1):120-123.
Kneebone GM, Kneebone R \& Gibson RA (1985). Fatty acid composition of breast milk from three racial groups from Penang, Malaysia. Am $J$ Clin Nutr 41(0002-9165):765-769.

Krešić G, Dujmović M, Mandić ML \& Delaš I (2013). Relationship between Mediterranean diet and breast milk fatty acid profile: a study in breastfeeding women in Croatia. Dairy Science \& Technology 93(3):287-301. doi: 10.1007/ s 13594-013-0125-6.

Lonnerdal B (2003). Nutritional and physiologic significance of human milk proteins. Am J Clin Nutr 77(6):1537S-1543. doi: 10.131/nr.2003. sept. 295.

Lucas A, Hudson G, Simpson P, Cole T \& Baker B (1987). An automated enzymic micromethod for the measurement of fat in human milk. $J$ Dairy Res 54(4):487-492. doi: 10.1017/ S0022029900025693.

Mamun AA, O'Callaghan MJ, Williams GM, Najman JM, Callaway L \& McIntyre HD (2015). Breastfeeding is protective to diabetes risk in young adults: a longitudinal study. Acta Diabetol 52(5):837-844. doi: $10.1007 /$ s00592014-0690-z.

Maru M, Birhanu T \& Tessema DA (2013). Calcium, magnesium, iron, zinc and copper, compositions of human milk from populations with cereal and 'enset' based diets. Ethiop $J$ Hlth Sci 23:90-97.

Nor Azwani MS, Siti Munirah AB, Mohd Safwan AR \& Wan Azdie MAB (2018). Perception on Postpartum Dietary Practices Among Malay Women in Hospital Tengku Ampuan Afzan (HTAA), Kuantan, Pahang. IJAHS 2(1):244-264.

Nommsen LA, Lovelady CA, Heinig MJ, Lonnerdal B \& Dewey KG (1991) Determinants of energy, protein, lipid, and lactose concentrations in human milk during the first 12 mo of lactation: the DARLING Study. Am J Clin Nutr 53:457465.

Ogechi UP \& Irene II (2013). Protein and amino acid composition of breast milk of mothers in Umuahia, Urban Nigeria. Euro $J$ Exp Bio 3(3):605-608.

Picciano MF (2001). Nutrient composition of human milk. Pediatr Clin North Am 48(1):5367. doi: 10.1016/S0031-3955(05)70285-6.

Poh BK, Wong YP \& Karim NA (2005). Postpartum Dietary Intakes and Food Taboos Among Chinese Women Attending Maternal and Child Health Clinics and Maternity Hospital, Kuala Lumpur. J Nutr 11(1):1-21. 
Qian J, Chen T, Lu W, Wu S \& Zhu J (2010). Breast milk macro- and micronutrient composition in lactating mothers from suburban and urban Shanghai. J Paediatr Child Hlth 46(3):115-120. doi: 10.1111/j.1440-1754.2009.01648.x.

Silva MHL, Silva MTC, Brandao SCC, Gomes JC, Peternelli LA \& Franceschini S (2005). Fatty acid composition of mature breast milk in Brazilian women. Food Chem 93(2):297-303. http: / / doi. org/10.1016/j.foodchem.2004.09.026.

Soliman SM, Soliman AM \& Bakr MS (2014). Relationships between maternal nutritional status, quantity and composition of breast milk in Egypt. AJAST 2(2):59-64.

Suraya S \& Jamaludin S (2014). Beliefs and practises surrounding postpartum. Soc Sci Res (June):409-417.

Tee ES, Mohd Ismail N, Mohd Nasir A \& Khatijah I (1997). Nutrient Composition of Malaysian Foods. Institute for Medical Research, Kuala Lumpur.

United States Department of Agriculture (USDA) Nutrient Data Laboratory (NDL) (2006). USDA National Nutrient Database for Standard Reference, Release 19. 2006. From https://fdc. nal.usda.gov.
WHO (2009). Infant and young child feeding. World Health Organization, Geneva.

WHO (2011). Infant and young child feeding. World Health Organization, Geneva.

Willett W \& Stampfer MJ (1986). Total energy intake: Implications for epidemiologic analyses. Am J Epidemiol 124 (1):17-27. doi: 10.1093/ oxfordjournals.aje.a114366.

Yang T, Zhang Y, Ning Y, You L, Ma D, Zheng Y, Yang X, Li W, Wang J \& Wang P (2014). Breast milk macronutrient composition and the associated factors in urban Chinese mothers. Chin Med J (Engl) 127:1721-1725.

Yang T, Zhang L, Bao W \& Rong S (2018). Nutritional composition of breast milk in Chinese women: a systematic review. Asia Pac J Clin Nutr 27(3):491-502. doi: 10.6133/ apjen.042017.13. 